\title{
Novel Antioxidant Properties of Doxycycline
}

\author{
Dahn L. Clemens ${ }^{1,2,3}$, Michael J. Duryee ${ }^{1,2}{ }^{(0)}$, Cleofes Sarmiento ${ }^{4}$, Andrew Chiou ${ }^{1}$, \\ Jacob D. McGowan ${ }^{1}$, Carlos D. Hunter ${ }^{1,2}$, Sarah L. Schlichte ${ }^{4}$, Jun Tian ${ }^{4}$, Lynell W. Klassen ${ }^{1,2}$, \\ James R. O'Dell ${ }^{1,2}$, Geoffrey M. Thiele ${ }^{1,2}{ }^{(0)}$, Ted R. Mikuls ${ }^{1,2}$, Matthew C. Zimmerman ${ }^{4,+}$ (i) \\ and Daniel R. Anderson $1, *,+$
}

1 Department of Internal Medicine, University of Nebraska Medical Center, 982650 Nebraska Medical Center, Omaha, NE 68198-2265, USA; dclemens@unmc.edu (D.L.C.); mduryee@unmc.edu (M.J.D.); andrew.chiou@unmc.edu (A.C.); jake.mcgowan@unmc.edu (J.D.M.); cdhunter@unmc.edu (C.D.H.); lklassen@unmc.edu (L.W.K.); jrodell@unmc.edu (J.R.O.); gthiele@unmc.edu (G.M.T.); tmikuls@unmc.edu (T.R.M.)

2 Veterans Affairs (VA) Nebraska-Western Iowa Health Care System, 4101 Woolworth Ave, Omaha, NE 68105, USA

3 Fred and Pamela Buffet Cancer Center, Omaha, NE 68114, USA

4 Department of Cellular and Integrative Physiology, University of Nebraska Medical Center, 982650 Nebraska Medical Center, Omaha, NE 68198-2265, USA; cleofes.sarmiento@unmc.edu (C.S.); sarah.schlichte@unmc.edu (S.L.S.); jtian@unmc.edu (J.T.); mczimmerman@unmc.edu (M.C.Z.)

* Correspondence: danderso@unmc.edu

$\dagger$ Contributed equally as corresponding author.

Received: 20 November 2018; Accepted: 13 December 2018; Published: 17 December 2018

\begin{abstract}
Doxycycline (DOX), a derivative of tetracycline, is a broad-spectrum antibiotic that exhibits a number of therapeutic activities in addition to its antibacterial properties. For example, DOX has been used in the management of a number of diseases characterized by chronic inflammation. One potential mechanism by which DOX inhibits the progression of these diseases is by reducing oxidative stress, thereby inhibiting subsequent lipid peroxidation and inflammatory responses. Herein, we tested the hypothesis that DOX directly scavenges reactive oxygen species (ROS) and inhibits the formation of redox-mediated malondialdehyde-acetaldehyde (MAA) protein adducts. Using a cell-free system, we demonstrated that DOX scavenged reactive oxygen species (ROS) produced during the formation of MAA-adducts and inhibits the formation of MAA-protein adducts. To determine whether DOX scavenges specific ROS, we examined the ability of DOX to directly scavenge superoxide and hydrogen peroxide. Using electron paramagnetic resonance (EPR) spectroscopy, we found that DOX directly scavenged superoxide, but not hydrogen peroxide. Additionally, we found that DOX inhibits MAA-induced activation of Nrf2, a redox-sensitive transcription factor. Together, these findings demonstrate the under-recognized direct antioxidant property of DOX that may help to explain its therapeutic potential in the treatment of conditions characterized by chronic inflammation and increased oxidative stress.
\end{abstract}

Keywords: doxycycline; oxidative stress; post transnational modification; anti-oxidant; electron paramagnetic resonance

\section{Introduction}

Tetracyclines are a family of broad spectrum, well-tolerated antibiotics. Since their discovery over 70 years ago, the modification of naturally occurring tetracyclines and synthesis of novel derivatives has generated numerous compounds. One of the derivatives commonly used clinically is doxycycline (DOX). The chemical structure of DOX is provided in Figure 1. DOX and other tertacyclines exhibit 
a number of therapeutic properties in addition to their antibacterial activities. These activities include anti-inflammatory, anti-apoptotic, and antioxidant activities [1-5]. Because of these pleotropic actions, DOX and other derivatives of tetracycline have been used in the treatment of a wide variety of diseases. Interestingly, DOX and other derivatives of tetracycline appear to be effective in the treatment of diseases associated with chronic inflammation, including abdominal aortic aneurysms, multiple sclerosis, gingivitis, and rheumatoid arteritis [1-4,6,7].

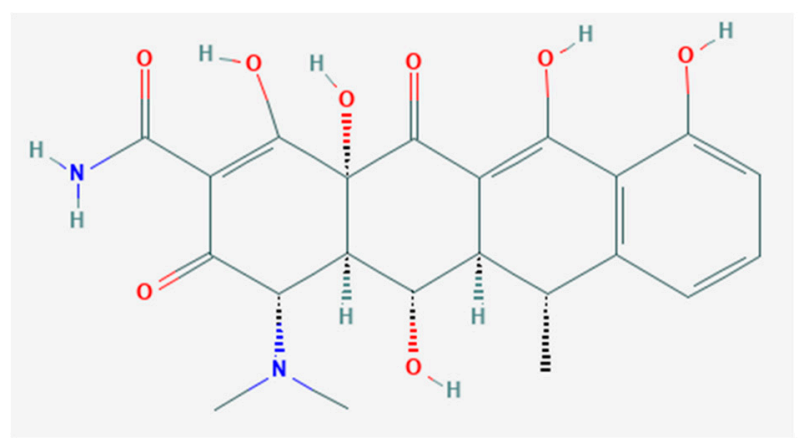

Figure 1. Structure of Doxycycline (DOX) $\mathrm{C}_{22} \mathrm{H}_{24} \mathrm{~N}_{2} \mathrm{O}_{8}$. Image taken from The National Center for Biotechnology Information. PubChem Compound Database; CID = 54671203, https: / pubchem.ncbi. nim.nih.gov/ coumpund/54671203 (accessed on 12 December 2018).

Chronic inflammation is commonly associated with oxidative stress. Oxidative stress occurs when the levels of reactive oxygen species (ROS) exceed the capacity of the endogenous antioxidant defense mechanisms. Oxidative stress can initiate inflammatory reactions. Likewise, inflammatory reactions can result in the production of ROS. Because of this, inflammation and oxidative stress, can establish a self-perpetuating cycle resulting in chronic inflammation.

One consequence of the oxidative stress associated with chronic inflammation is lipid peroxidation. Lipid peroxidation in turn, can initiate a self-sustaining reaction resulting in continued lipid peroxidation and perpetuation of inflammation. A major by-product of lipid peroxidation is malondialdehyde (MDA) [8,9]. MDA can spontaneously degrade to form acetaldehyde (AA) [10]. MDA and AA can interact and covalently bind amino groups of proteins and lipoproteins, primarily the $\varepsilon$-amino groups of lysines within these molecules, forming highly stable malondialdehyde-acetaldehyde (MAA) adducts [11-14]. MAA-adducts are themselves highly immunogenic, initiating robust pro-inflammatory responses providing a link between oxidative stress and inflammation [15-18]. Therefore, MAA modified proteins and lipoproteins are not only by-products of oxidative stress but may link oxidative stress and inflammation and play a critical role in the pathogenesis of chronic inflammatory diseases.

Considering the well-described link between oxidative stress and chronic inflammation and the fact that DOX has shown benefit in the treatment of some chronic inflammatory diseases, we tested the hypothesis that DOX acts as an antioxidant and directly scavenges ROS to inhibit the production of MAA-adducts. In this report, we demonstrate that DOX is able to directly scavenge superoxide, but not hydrogen peroxide, and inhibits the formation of MAA-adducts. Furthermore, we report that DOX alters intracellular redox signaling as demonstrated by its ability to inhibit the activation of Nrf2, a redox-sensitive transcription factor [19]. The direct antioxidant activity of DOX may be an under-recognized mechanism by which DOX is effective as a treatment for chronic inflammatory diseases. 


\section{Results}

\subsection{Doxycycline Attenuates MAA-Protein Adduct Formation}

To determine whether DOX inhibits the generation of MAA-adducts, we produced MAA-adducts in a cell-free system, by incubating MDA and AA (in a 2:1 molar ratio) with ALB to form MAA-ALB. The formation of MAA-ALB was monitored by its autofluorescence [14]. As shown in Figure 2, the fluorescence of the MDA, AA and ALB reaction increased compared with the ALB and vehicle control reaction. Inclusion of pharmaceutical DOX to the MDA, AA, and ALB reaction significantly attenuated the increase in fluorescence at all time points investigated, indicating decreased formation of MAA-ALB.

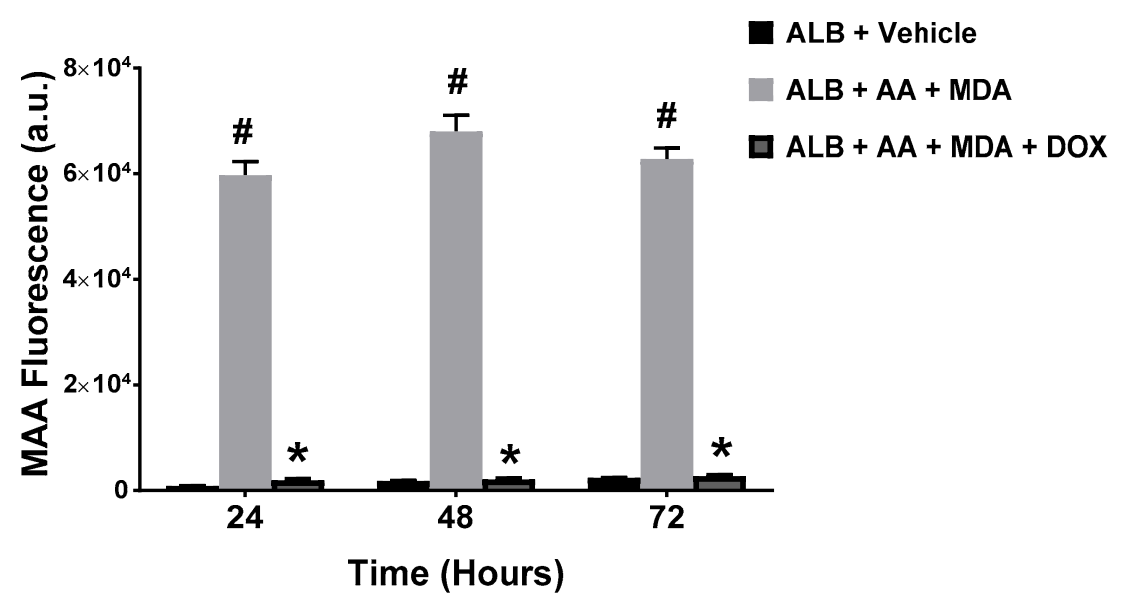

Figure 2. Pharmaceutical Doxycycline (DOX) Inhibits the Formation of MAA-Protein Adducts In Vitro. Human serum albumin (ALB, $1 \mathrm{mg} / \mathrm{mL}$ ) was incubated at $37^{\circ} \mathrm{C}$ with $2 \mathrm{mM}$ malondialdehyde (MDA) and $1 \mathrm{mM}$ acetaldehyde (AA), in the presence or absence of $1 \mathrm{mg} / \mathrm{mL}$ pharmaceutical DOX. The formation of MAA-adducted ALB was monitored fluorometrically (excitation $398 \mathrm{~nm}$ and emission $460 \mathrm{~nm}$ ) at 24, 48, and $72 \mathrm{~h}$. The inclusion of DOX significantly inhibited the formation of the MAA-ALB at all time points $\left({ }^{*} p<0.0001\right)$. Increased MAA fluorescence compared to ALB + Vehicle $\left({ }^{\#} p<0.0001\right)$ $N=10$.

\subsection{Doxycycline Decreases ROS Produced during the Generation of MAA-Adducts}

ROS are produced by the interaction of MDA and AA with amino groups of proteins, primarily the $\varepsilon$-amino group of lysines [20,21]. Because DOX attenuated the formation of MAA-ALB (Figure 2), we also investigated whether DOX decreased the levels of ROS produced during the formation of MAA-protein adducts. To accomplish this, ALB was incubated with MDA and AA in the presence or absence of $1 \mathrm{mg} / \mathrm{mL}$ pharmaceutical DOX, and ROS were measured by EPR spectroscopy. The results presented in Figure 3 demonstrate that incubation of MDA with AA and ALB produced ROS as demonstrated by the increase in the EPR spectrum amplitude (which is directly proportional to the levels of ROS in the sample) over the $72 \mathrm{~h}$ time period. In contrast, inclusion of DOX markedly reduced the increase in the EPR spectrum amplitude, indicating that DOX directly scavenges the ROS produced during MAA-adduct formation. 

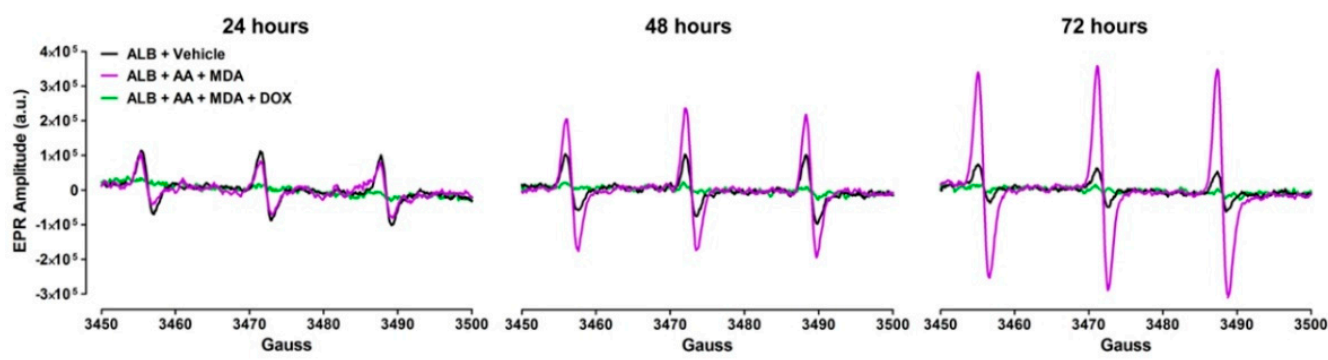

Figure 3. Pharmaceutical Doxycycline (DOX) Decreases ROS Levels Generated by MAA-Adduct Formation. Human serum albumin (ALB, $1 \mathrm{mg} / \mathrm{mL}$ ) was incubated at $37{ }^{\circ} \mathrm{C}$ with $2 \mathrm{mM}$ malondialdehyde (MDA) and $1 \mathrm{mM}$ acetaldehyde (AA), in the presence or absence of $1 \mathrm{mg} / \mathrm{mL}$ pharmaceutical DOX for 24, 48, and $72 \mathrm{~h}$. EPR spectroscopy was performed to determine the levels of ROS. Representative EPR spectra are presented. Control samples contained only albumin and vehicle. To detect levels of ROS, all reactions were incubated with $200 \mu \mathrm{M}$ of the EPR spectroscopy spin probe $\mathrm{CMH}$ for the final $30 \mathrm{~min}$ of reaction time. a.u. = arbitrary units.

\subsection{Doxycycline Inhibits MAA-ALB-Induced Activation of Nrf2.}

To expand upon the cell-free studies described above and gain insight into whether DOX acts as an antioxidant in biological systems, we utilized HEK 293 Nrf2/ ARE cells to investigate the capacity of pharmaceutical DOX to inhibit ROS-mediated activation of Nrf2, a redox-sensitive transcription factor. Culturing HEK 293 Nrf2/ARE cells in media containing MDA and AA, in the presence or absence of ALB for $24 \mathrm{~h}$ significantly increased Nrf2 activation, as demonstrated by increased luminescence (Figure 4). Nrf2 activation was significantly attenuated by the inclusion of $1 \mathrm{mg} / \mathrm{mL}$ pharmaceutical DOX indicating that the elevated levels of intracellular ROS induced by MDA and AA-mediated formation of MAA-adducts are scavenged by DOX. These results demonstrate that the ROS intermediate of the MAA-adduct or ROS produced during MAA-adduction are able to activate/stabilize Nrf2 and that DOX is able to scavenge these oxidants.

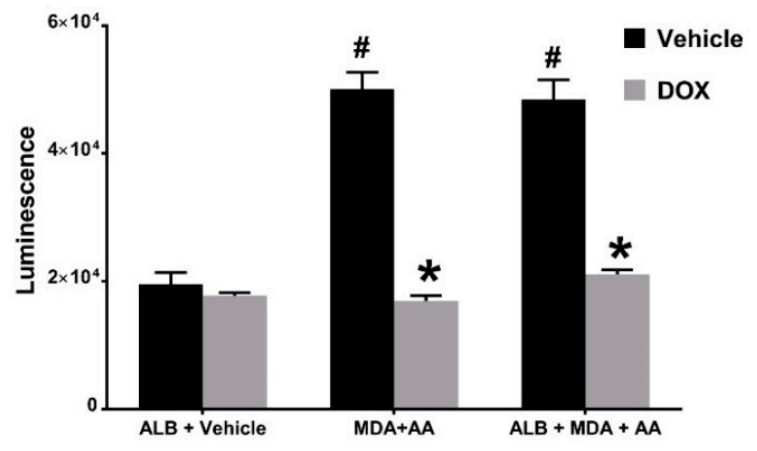

Figure 4. Pharmaceutical Doxycycline (DOX) Inhibits Cellular Redox Signaling Induced by MAA-Adduct Formation. HEK293 cells containing a Nrf2/ARE-responsive element driving luciferase expression were incubated for $24 \mathrm{~h}$ in the presence or absence of $1 \mathrm{mg} / \mathrm{mL}$ pharmaceutical DOX and either $25 \mu \mathrm{g} / \mathrm{mL}$ ALB, or $2 \mathrm{mM}$ MDA and $1 \mathrm{mM}$ AA, or $25 \mu \mathrm{g} / \mathrm{mL}$ ALB, $2 \mathrm{mM}$ MDA, and $1 \mathrm{mM}$ AA. Significantly decreased with the addition of DOX $(* p<0.0001)$. Significantly increased compared to ALB + Vehicle $\left({ }^{\#} p<0.0001\right) N=5$.

\subsection{Pharmaceutical Doxycycline Directly Scavenges Superoxide and Hydrogen Peroxide}

To determine whether pharmaceutical DOX directly scavenges specific ROS, namely $\mathrm{O}_{2}{ }^{\bullet-}$, we utilized cell-free reactions containing $50 \mu \mathrm{M} \mathrm{HX}$ and $10 \mathrm{mU} / \mathrm{mL}$ XO to generate $\mathrm{O}_{2}{ }^{\bullet-}$, which was measured by EPR spectroscopy. The EPR spectrum amplitude obtained from reactions containing HX, $\mathrm{XO}$, and the $\mathrm{CMH}$ spin probe was significantly greater than the amplitude obtained from reactions containing only CMH (Figure 5A). This increase in EPR spectrum amplitude was virtually abolished 
by pharmaceutical DOX, indicating that pharmaceutical DOX directly scavenges $\mathrm{O}_{2}{ }^{\bullet-}$. Corroborating the fidelity of the assay, the EPR spectrum amplitude was also abolished by SOD (Figure 5A).

A.

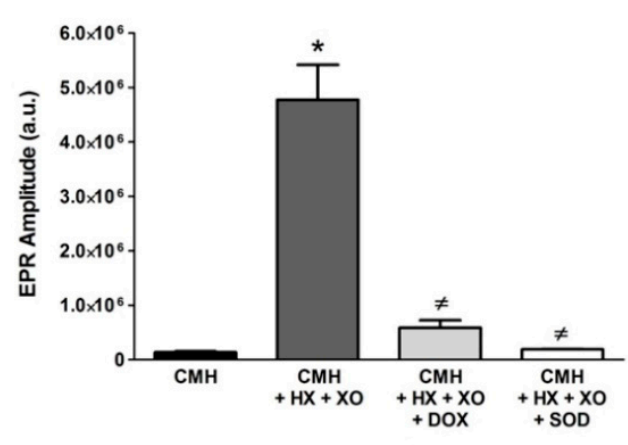

B.

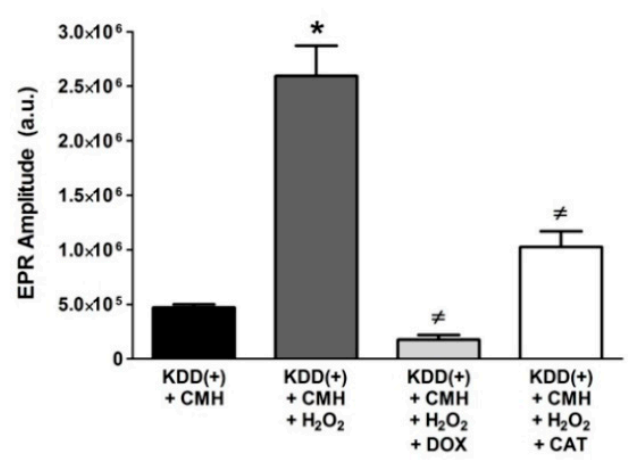

Figure 5. Pharmaceutical Doxycycline (DOX) Directly Scavenges Superoxide $\left(\mathrm{O}_{2}{ }^{\bullet-}\right)$ and Hydrogen Peroxide $\left(\mathrm{H}_{2} \mathrm{O}_{2}\right)$. (A) EPR spectroscopy was performed in $\mathrm{O}_{2}{ }^{\bullet-}$ generating reaction containing $50 \mu \mathrm{M}$ hypoxanthine (HX), $10 \mathrm{mU} / \mathrm{mL}$ of xanthine oxidase $(\mathrm{XO})$, and $200 \mu \mathrm{M}$ of $\mathrm{CMH}$ at $37^{\circ} \mathrm{C}$ for $30 \mathrm{~min}$. To determine the ability of DOX to scavenge $\mathrm{O}_{2}{ }^{\bullet-}$ the reactions were performed in the presence of absence $1 \mathrm{mg} / \mathrm{mL}$ pharmaceutical DOX. Control reactions included SOD, a known direct scavenger of $\mathrm{O}_{2}{ }^{\bullet-}$. (B) The ability of pharmaceutical DOX to scavenge $\mathrm{H}_{2} \mathrm{O}_{2}$ was determined by EPR spectroscopy in $\mathrm{KDD}(+)$ buffer containing $10 \mu \mathrm{M} \mathrm{H}_{2} \mathrm{O}_{2}$ in the presence or absence of $1 \mathrm{mg} / \mathrm{mL}$ pharmaceutical DOX at $37{ }^{\circ} \mathrm{C}$ for $30 \mathrm{~min}$. Control reactions included catalase (CAT), a known direct scavenger of $\mathrm{H}_{2} \mathrm{O}_{2}$. $\left({ }^{*} p<0.05\right)$ vs. $\mathrm{CMH}(\mathbf{A})$ or $\mathrm{KDD}(+)$ and $\mathrm{CMH}(\mathbf{B}),(\neq p<0.05)$ vs. $\mathrm{CMH}, \mathrm{HX}$, and $\mathrm{XO}(\mathbf{A})$ or $\mathrm{KDD}(+)$, $\mathrm{CMH}$, and $\mathrm{H}_{2} \mathrm{O}_{2}($ B). $\mathrm{N}=3-6$.

Next, we investigated whether DOX could directly scavenge other ROS, particularly $\mathrm{H}_{2} \mathrm{O}_{2}$. To accomplish this, we utilized EPR spectroscopy with the CMH spin probe and $\mathrm{KDD}(+)$ buffer. As described in the Methods, $\mathrm{KDD}(+)$ buffer contains $\mathrm{HRP}$ and AAP, which mediate $\mathrm{H}_{2} \mathrm{O}_{2}$-dependent oxidation of $\mathrm{CMH}$ to the EPR-detectable stable nitroxide radical [22]. Figure $5 \mathrm{~B}$ shows that $\mathrm{H}_{2} \mathrm{O}_{2}$ significantly increased the amplitude of the EPR spectrum compared with reactions performed in its absence. Importantly, pharmaceutical DOX dramatically decreased the EPR spectrum amplitude, thus demonstrating that it directly scavenges $\mathrm{H}_{2} \mathrm{O}_{2}$. To ensure the integrity of the assay, separate reactions were performed in the presence of $500 \mathrm{U} / \mathrm{mL}$ catalase, an antioxidant enzyme that directly scavenges $\mathrm{H}_{2} \mathrm{O}_{2}$. As expected, catalase also inhibited the $\mathrm{H}_{2} \mathrm{O}_{2}$-induced increase in EPR spectrum amplitude. Unexpectedly, however, pharmaceutical DOX was more effective than catalase at reducing the amplitude of the EPR spectra.

\subsection{Ascorbic Acid (ASC) in Pharmaceutical DOX Reduces the CM Radical Spin Probe to Non-Radical CMH}

Because of the unexpected result that pharmaceutical DOX scavenged $\mathrm{H}_{2} \mathrm{O}_{2}$ more effectively than catalase (Figure 5B), we more closely examined the components of the pharmaceutical DOX. Interestingly, we found that the pharmaceutical DOX preparation contains ascorbic acid (ASC) (i.e., Vitamin C), a well-characterized antioxidant [23]. Therefore, to determine the contribution of ASC to the pharmaceutical DOX results (Figure 5), we performed EPR spectroscopy using $\mathrm{CM}^{\bullet}$, a stable radical form of the $\mathrm{CMH}$ spin probe, and $4.8 \mathrm{mg} / \mathrm{mL}$ ASC, which is the concentration of ASC present in the previous reactions containing pharmaceutical DOX. We found that incubation of the stable $\mathrm{CM}^{\bullet}$ with ASC abolished the EPR spectrum amplitude (Figure 6), presumably by reducing the stable radical to the non-radical, non-EPR detectable CMH. Thus, the decrease in EPR spectrum amplitude we observed with pharmaceutical DOX is at least partially mediated by the presence of ASC. 


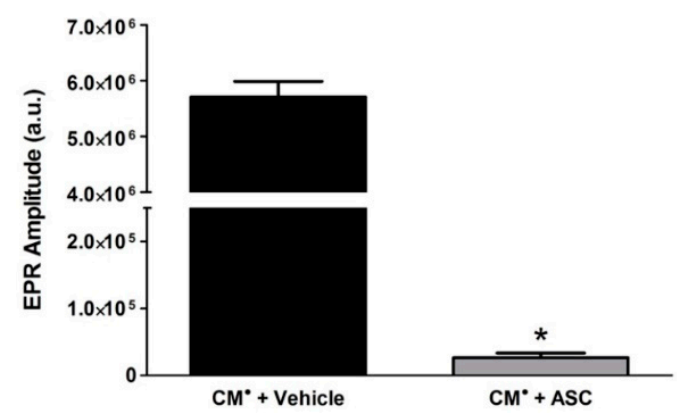

Figure 6. Ascorbic Acid (ASC) Reduces Stable $\mathrm{CM}^{\bullet}$ to Non-EPR Detectable $\mathrm{CMH}$ Increase. EPR spectroscopy was performed using $200 \mu \mathrm{M}$ of the stable $\mathrm{CM}^{\bullet} \mathrm{EPR}$ probe in the presence or absence of $4.8 \mathrm{mg} / \mathrm{mL}$ of ASC. $\left.{ }^{*} p<0.0001\right)$ vs. $\mathrm{CM}^{\bullet}$ and vehicle. $N=3$.

2.6. Doxycycline in the Absence of Ascorbic Acid Scavenges Superoxide and Inhibits Intracellular Redox Signaling

Because ASC reduced the stable EPR spin probe radical to the non-EPR detectable form, we repeated the aforementioned EPR spectroscopy experiments using ASC-free DOX. ASC-free DOX $(1 \mathrm{mg} / \mathrm{mL})$ significantly attenuated the EPR spectrum amplitude obtained from cell-free reactions containing $\mathrm{CMH}, \mathrm{HX}$, and $\mathrm{XO}$ (Figure 7A), indicating that DOX itself is capable of directly scavenging $\mathrm{O}_{2}{ }^{\bullet-}$. In contrast, ASC-free DOX failed to impact the EPR spectrum amplitude obtained from reactions containing the $\mathrm{KDD}(+)$ buffer, $\mathrm{CMH}$, and $\mathrm{H}_{2} \mathrm{O}_{2}$ (Figure 7B), which demonstrates that ASC-free DOX does not directly scavenge $\mathrm{H}_{2} \mathrm{O}_{2}$.
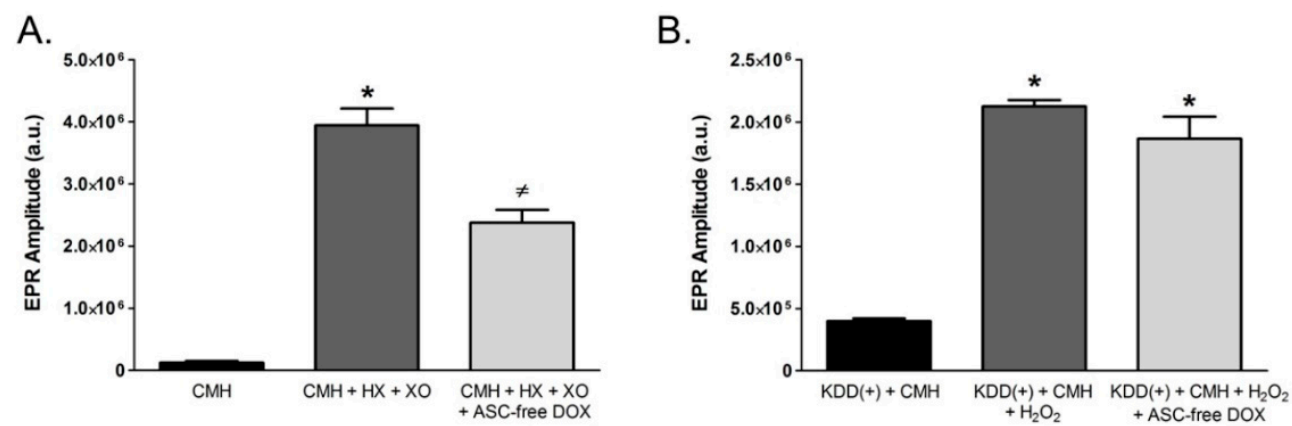

Figure 7. Ascorbic Acid-Free Doxycycline (ASC-free DOX) Directly Scavenges Superoxide. (A) EPR spectroscopy was performed in a $\mathrm{O}_{2}{ }^{\bullet-}$ generating reaction containing $50 \mu \mathrm{M}$ hypoxanthine $(\mathrm{HX})+10 \mathrm{mU} / \mathrm{mL}$ of xanthine oxidase $(\mathrm{XO}$,$) and 200 \mu \mathrm{M}$ of the spin probe, $\mathrm{CMH}$, at $37{ }^{\circ} \mathrm{C}$ for $30 \mathrm{~min}$. The ability of ascorbic acid-free DOX (ASC-free DOX) to scavenge $\mathrm{O}_{2}{ }^{\bullet-}$ was investigated in the presence or absence of $1 \mathrm{mg} / \mathrm{mL}$ ASC-free DOX. (B) The ability of ASC-free DOX to scavenge $\mathrm{H}_{2} \mathrm{O}_{2}$ was investigated in EPR spectroscopy reactions performed in $\mathrm{KDD}(+)$ buffer containing $10 \mu \mathrm{M} \mathrm{H}_{2} \mathrm{O}_{2}$. Reactions were carried out in the presence or absence of $1 \mathrm{mg} / \mathrm{ml}$ ASC-free DOX at $37^{\circ} \mathrm{C}$ for $30 \mathrm{~min}$. $\left({ }^{*} p<0.05\right)$ vs. $\mathrm{CMH}(\mathbf{A})$ or $\mathrm{KDD}(+)+\mathrm{CMH}(\mathbf{B}),(\neq p<0.05)$ vs. $\mathrm{CMH}+\mathrm{HX}+\mathrm{XO}(\mathbf{A}) \cdot N=4$.

To confirm that ASC-free DOX was capable of scavenging ROS, we repeated our MAA-adduct formation assay and investigated whether ASC-free DOX inhibited MAA-ALB generation. ASC-free DOX did indeed inhibit the formation of MAA-ALB at all times points investigated (Figure 8). 


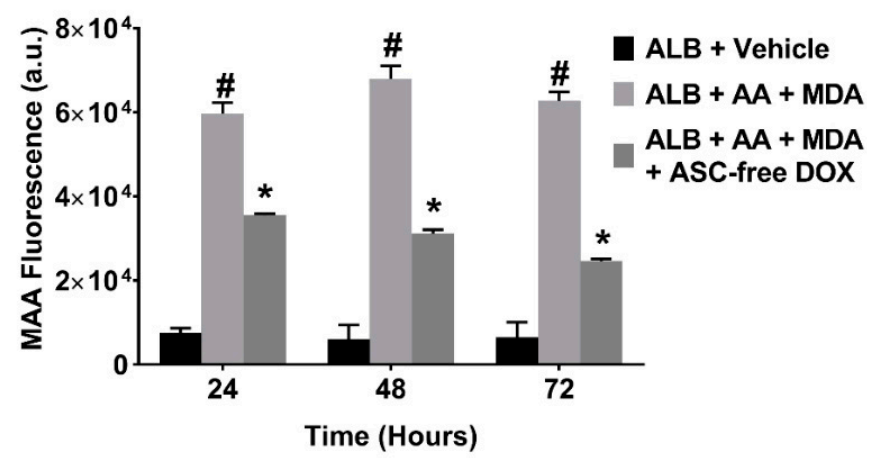

Figure 8. Ascorbic Acid-Free Doxycycline (ASC-free DOX) Inhibits MAA-Protein Adduction. Human serum albumin (ALB, $1 \mathrm{mg} / \mathrm{mL}$ ) was incubated at $37^{\circ} \mathrm{C}$ with $2 \mathrm{mM}$ malondialdehyde (MDA) and $1 \mathrm{mM}$ acetaldehyde (AA), in the presence or absence of ASC-free DOX $(1 \mathrm{mg} / \mathrm{mL})$. The formation of MAA-adducted ALB was monitored fluorometrically (excitation $398 \mathrm{~nm}$ and emission $460 \mathrm{~nm}$ ) at 24, 48, and $72 \mathrm{~h}$. The inclusion of ASC-free DOX significantly inhibited the formation of the MAA-ALB $\left({ }^{*} p<0.0001\right)$ vs. ALB + AA + MDA, formation of MAA-ALB was increased $(\# p<0.0001)$ vs. ALB + vehicle at the respective time-point. $N=4$.

We also repeated the HEK 293 Nrf2/ARE cell experiments to determine whether ASC-free DOX was able to inhibit Nrf2 activation induced by treatment with ALB, MDA and AA. The results demonstrated that DOX reduced the activation of Nrf2/ARE as indicated by a decrease in luminescence (Figure 9A). Additionally, $1 \mathrm{mg} / \mathrm{ml}$ ASC-free DOX was able to attenuate $\mathrm{H}_{2} \mathrm{O}_{2}$-induced $\mathrm{Nrf} 2$ activation (Figure 9B). Collectively, these results provide additional evidence that DOX, in the absence of ASC, scavenges specific $\mathrm{ROS}$, particularly $\mathrm{O}_{2}{ }^{\bullet}$.

A.

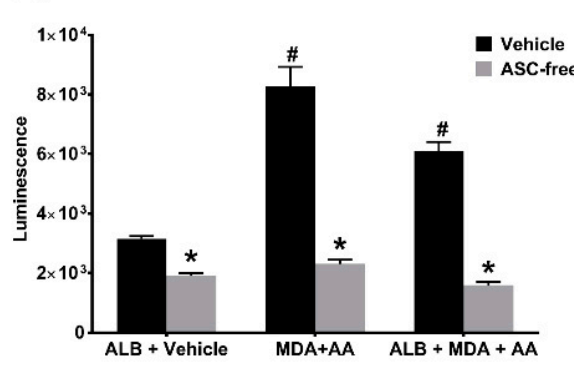

B.

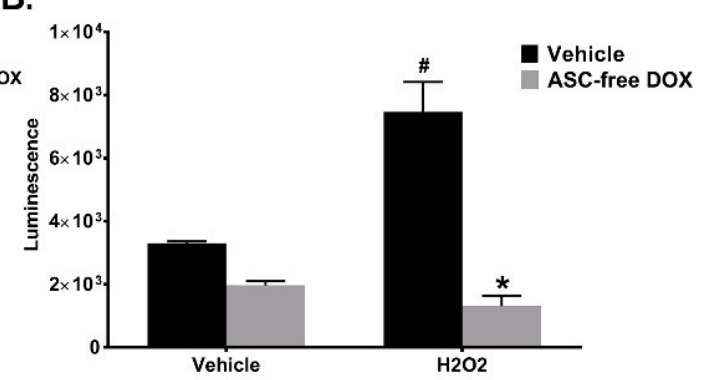

Figure 9. Ascorbic Acid-Free Doxycycline (ASC-free DOX) Inhibits Cellular Redox Signaling Induced by MAA-Adduct Formation. (A) HEK 293 cells containing a Nrf2/ARE-responsive element were incubated for $24 \mathrm{~h}$ in the presence or absence of $1 \mathrm{mg} / \mathrm{mL}$ ASC-free DOX and either ALB + vehicle, $\mathrm{MDA}+\mathrm{AA}$, or ALB + MDA + AA. Cells were lysed and luciferase activity determined. Significantly decreased in the presence of DOX $(* p<0.01)$. Significantly increased compared to ALB + Vehicle ( $p$ < 0.001). (B) HEK 293 cells containing a Nrf2/ARE-responsive element were incubated for $24 \mathrm{~h}$ with $10 \mu \mathrm{M} \mathrm{H}_{2} \mathrm{O}_{2}$ in the presence or absence of $1 \mathrm{mg} / \mathrm{mL}$ ASC-free DOX. Significantly decreased in the presence of DOX $\left({ }^{*} p<0.0001\right)$. Significantly increased compared to ALB + Vehicle $\left({ }^{\#} p<0.0001\right)$. $N=4-8$.

\section{Discussion}

Oxidative stress and inflammation are intimately related [24,25]. Because of this, oxidative stress is a critical factor in the maintenance of inflammation in many chronic inflammatory diseases. Oxidative stress occurs when the levels of ROS, such as $\mathrm{O}_{2}{ }^{\bullet-}, \bullet \mathrm{OH}$, or $\mathrm{H}_{2} \mathrm{O}_{2}$, exceed the capacity of cellular antioxidant systems to reduce them. If not reduced by endogenous antioxidants or scavenging pathways, ROS can cause cellular damage by oxidizing macromolecules such as DNA, proteins, lipids, and lipoproteins. Oxidative stress can also lead to lipid peroxidation, a self-sustaining reaction in which newly formed lipidperoxides are able to react with other lipids 
resulting in further production of lipidperoxides [13,26,27]. A by-product of lipid peroxidation is MAA-adduct formation. MAA adduction of proteins and lipoproteins has been demonstrated in the diseased tissue of numerous inflammatory diseases, including cardiovascular disease, alcoholic liver disease, smoking-related lung injury, rheumatoid arthritis, and atherosclerosis [15,28-32]. MAA modification of proteins and lipoproteins can affect their function and/or stability and cause cytotoxicity. Importantly, previous studies have clearly demonstrated that MAA-adducts are immunogenic $[15,32-34]$. Thus, MAA-adducts can initiate inflammatory responses, thereby potentially perpetuating the cycle of inflammation and oxidative stress associated with chronic inflammatory diseases $[17,35]$.

DOX and other derivatives of tetracycline demonstrate clinical benefit beyond their antibacterial activities [1]. A number of these compounds have been shown to have antioxidant activities $[1,36]$. Although the exact mechanism by which these compounds act as antioxidants is not known, it has been proposed that the phenol ring of these compounds is central to their ROS scavenging capabilities [36]. It is thought that the reaction of the phenol ring with ROS generates a phenol radical, which is relatively stable and unreactive because of resonance stabilization and steric hindrance by the side groups of the phenolic ring [36].

DOX and other tetracyclines such as minocycline have been used in the treatment of gingival disease, abdominal aortic aneurysms, rheumatoid arthritis, acne, neurological disorders such as multiple sclerosis, and have been proposed as a treatment for Alzheimer's disease $[2,3,5,6,37,38]$. All of these diseases have a component that is characterized by elevated ROS production and oxidative stress. In preclinical models, DOX has been shown to prevent periodontal disease by inhibiting oxidative stress [39], as well as to provide cardioprotection of hearts during cold storage by balancing oxidant/antioxidant levels [40]. Additionally, in a model of hypertension, DOX treatment reduced aortic matrix metalloproteinase (MMP) activity and ROS levels [41].

Because DOX has shown clinical benefit in the treatment of chronic inflammatory diseases and MAA-adducts are associated with many of these diseases, we investigated whether DOX was able to inhibit the formation of MAA-adducts. Using a cell-free system, we demonstrated that DOX inhibits MAA-adduct formation and reduces the production of ROS generated during their formation. Specifically, we demonstrated that DOX directly scavenges $\mathrm{O}_{2}{ }^{\bullet-}$. We expanded upon these cell-free experiments by also demonstrating that DOX inhibits MAA-adduct-induced intracellular redox signaling, as measured by Nrf2 stabilization/activation. The Nrf2-dependant expression of luciferase was dramatically reduced when DOX was included in the culture media demonstrating that DOX acts as an antioxidant in a biological system. Interestingly, although DOX failed to scavenge $\mathrm{H}_{2} \mathrm{O}_{2}$ in cell-free studies, DOX significantly reduced Nrf2-dependant expression of luciferase induced by $\mathrm{H}_{2} \mathrm{O}_{2}$. These seemingly paradoxical results could stem from the capacity of DOX to scavenge other oxidants, such as the hydroxyl radical or lipid peroxides, produced as a result of the interaction of $\mathrm{H}_{2} \mathrm{O}_{2}$ with other molecules. Thus, DOX is able to moderate free radical levels, and the production of the pro-inflammatory MAA-adducts. It is tempting to speculate that DOX may thereby break the cycle of oxidative stress and inflammation and that this is the mechanism of action by which DOX provides clinical benefit in the treatment of chronic inflammatory diseases.

We have recently shown that methotrexate (MTX), a commonly prescribed medication that has demonstrated benefit in the treatment of chronic inflammatory diseases, is able to act as an antioxidant by scavenging $\mathrm{O}_{2}{ }^{\bullet-}$ [20]. It has been proposed that the side chains of the phenolic rings of DOX provide it with its antioxidant capability [36]. Inspection of the primary structure of MTX reveals that MTX also possesses side groups that are capable of acting as electron donors. Similar to DOX, we speculate that the antioxidant properties of MTX relate to its side groups, which act as electron donors and directly scavenge ROS. By this mechanism, DOX and MTX could reduce free radicals such as $\mathrm{O}_{2}{ }^{\bullet-}$ and perhaps other ROS. Furthermore, we suggest that the ability to act as ROS scavengers may be a common mechanism by which water soluble medications such as DOX and MTX provide beneficial, pleotropic activities. 
In summary, we have demonstrated that DOX has direct and specific antioxidant properties, which may explain why DOX and other tetracyclines exhibit clinical benefit beyond their antibacterial properties. DOX is capable of inhibiting MAA-adduct formation, and scavenging ROS generated during their production. More specifically, DOX is able to directly scavenge $\mathrm{O}_{2}{ }^{-}$, and can attenuate intracellular redox signaling. Because ROS, oxidative stress, and inflammation are intertwined [42,43], we speculate that, by reducing $\mathrm{O}_{2}{ }^{\bullet-}$ levels, DOX reduces inflammation, thereby providing benefit in the treatment of chronic inflammatory diseases. Our findings indicate that the non-antibiotic clinical efficacy of DOX observed in the treatment of these chronic inflammatory diseases may be explained, at least in part, by its direct and specific antioxidant properties.

\section{Materials and Methods}

\subsection{Malondialdehyde-Acetaldehyde (MAA)-Protein Adduct Formation}

MAA-adducted human serum albumin (MAA-ALB) was produced by incubating $1 \mathrm{mg} / \mathrm{mL}$ of human serum albumin (ALB) (Talecris Biotherapeutics Inc., Research Triangle Park, NC, USA) with $2 \mathrm{mM}$ MDA, and $1 \mathrm{mM} \mathrm{AA}$, in phosphate-buffered saline (PBS), for 24,48 , or $72 \mathrm{~h}$ at $37{ }^{\circ} \mathrm{C}$ as previously described [14]. To determine the ability of pharmaceutical DOX (Fresenius Kabi, Lake Aurich, IL, USA) to inhibit the formation of MAA-ALB, $1 \mathrm{mg} / \mathrm{mL}$ of DOX was included in these assays.

Additionally, to confirm the role of DOX in these assays, both $4.8 \mathrm{mg} / \mathrm{mL}$ ascorbic acid (ASC), which is a component of pharmaceutical DOX, and doxycycline hyclate from Sigma-Aldrich (St. Louis, MO, USA), which is ascorbic acid-free (ASC-free DOX), were tested for the ability to inhibit MAA-adduct formation. The formation of MAA-ALB was monitored by its autofluorescence (excitation $398 \mathrm{~nm}$ and emission $460 \mathrm{~nm}$ ) using a Turner Biosystems (Sunnyvale, CA, USA) LS-5B spectrofluorometer as previously described [14].

\subsection{Electron Paramagnetic Resonance (EPR) Spectroscopy}

Using electron paramagnetic resonance (EPR) spectroscopy, we have previously demonstrated that the MAA adduction of ALB produces ROS [20]. Employing this technique, we investigated the ability of DOX to scavenge ROS. Briefly, we measured levels of ROS in $1 \mathrm{~mL}$ cell-free reactions containing $1 \mathrm{mg} A \mathrm{ALB}, 2 \mathrm{mM}$ MDA, and $1 \mathrm{mM}$ AA with or without $1 \mathrm{mg} / \mathrm{mL}$ pharmaceutical DOX. Control samples contained ALB alone in vehicle (i.e., PBS). Reactions were incubated for 24,48 , or $72 \mathrm{~h}$ at $37{ }^{\circ} \mathrm{C}$. After incubation, $200 \mu \mathrm{M}$ of the EPR spin probe, 1-hydroxy-3-methoxycarbonyl-2,2,5,5-tetramethylpyrrolidine $(\mathrm{CMH})$, was added to each reaction and incubated for $30 \mathrm{~min}$ at $37^{\circ} \mathrm{C}$. Fifty microliters of each sample were then loaded into a glass capillary tube and analyzed in a Bruker e-scan EPR spectrometer. ROS produced during the formation of MAA-ALB reacted with the $\mathrm{CMH}$ spin probe to produce a stable nitroxide radical $\left(\mathrm{CM}^{\bullet}\right)$, which yielded a characteristic 3-peak EPR spectrum [44]. The level of ROS in the sample was directly proportional to the amplitude of the EPR spectrum [44]. The EPR spectrometer settings used for these and all subsequent experiments were: field sweep width $60.0 \mathrm{G}$, microwave frequency $9.74 \mathrm{kHz}$, microwave power $21.90 \mathrm{~mW}$, modulation amplitude $2.37 \mathrm{G}$, conversion time $10.24 \mathrm{~ms}$, and time constant $40.96 \mathrm{~ms}$.

To determine whether DOX directly scavenges specific ROS, particularly superoxide $\left(\mathrm{O}_{2}{ }^{\bullet-}\right)$, cell-free reactions containing hypoxanthine (HX) and xanthine oxidase $(\mathrm{XO})$, which produce $\mathrm{O}_{2}{ }^{\bullet-}$, were utilized [19]. Samples were prepared with $200 \mu \mathrm{M} \mathrm{CMH}$ spin probe, $50 \mu \mathrm{M} \mathrm{HX}$, and $10 \mathrm{mU} / \mathrm{mL}$ XO with or without $1 \mathrm{mg} / \mathrm{mL}$ DOX in $100 \mu \mathrm{L}$ of EPR buffer $(99 \mathrm{mM} \mathrm{NaCl}, 4.69 \mathrm{mM} \mathrm{KCl}, 2.5 \mathrm{mM}$ $\mathrm{CaCl}_{2}, 1.2 \mathrm{mM} \mathrm{MgSO}_{4}, 25 \mathrm{mM} \mathrm{NaHCO}_{3}, 1.03 \mathrm{mM} \mathrm{KH}_{2} \mathrm{PO}_{4}, 5.6 \mathrm{mM}$ D-glucose, $20 \mathrm{mM}$ HEPES) $\mathrm{pH}$ 7.4 , supplemented with $5 \mu \mathrm{M}$ and $25 \mu \mathrm{M}$ of the metal chelators diethyldithiocarbamate (DETC) and deferoxamine, respectively (19). To ensure the fidelity of the assay and confirm the measurement of $\mathrm{O}_{2}{ }^{\bullet-}$ specifically, control reactions containing $\mathrm{CMH}, \mathrm{HX}, \mathrm{XO}$, and $400 \mathrm{U}$ copper/zine superoxide dismutase (SOD) were performed. SOD is an antioxidant enzyme that specifically catalyzes the 
dismutation of $\mathrm{O}_{2}{ }^{\bullet-}$ into hydrogen peroxide $\left(\mathrm{H}_{2} \mathrm{O}_{2}\right)$ and oxygen. Samples were incubated at $37^{\circ} \mathrm{C}$ for $30 \mathrm{~min}$ and the EPR spectra were determined.

Reactions to determine the ability of DOX to directly scavenge $\mathrm{H}_{2} \mathrm{O}_{2}$ were performed with $200 \mu \mathrm{M} \mathrm{CMH}$ and $10 \mu \mathrm{M} \mathrm{H}_{2} \mathrm{O}_{2}$ in $100 \mu \mathrm{L}$ of $\mathrm{KDD}(+)$ buffer (pH 7.4). $\mathrm{KDD}(+)$ buffer is EPR buffer supplemented with $1 \mathrm{mM}$ 4-acetamidophenol (AAP), $1 \mathrm{U} / \mathrm{mg}$ horseradish peroxidase (HRP), and $200 \mu \mathrm{M}$ diethylenetriaminepentaacetic acid (DTPA) [19]. In KDD(+) buffer, HRP and AAP mediate the $\mathrm{H}_{2} \mathrm{O}_{2}$-dependent oxidation of $\mathrm{CMH}$ to the stable nitroxide radical [22]. Catalase, a direct scavenger of $\mathrm{H}_{2} \mathrm{O}_{2}$, was used to ensure the fidelity of this assay. Samples were incubated for $30 \mathrm{~min}$ at $37^{\circ} \mathrm{C}$ and EPR spectra were obtained, as described above.

\subsection{Cellular Redox Signaling}

To determine the ability of DOX to modulate cellular redox signaling pathways, which are activated by the generation of MAA-adducts, we employed HEK 293 cells stably transfected with a nuclear factor (erythroid derived 2)-like 2/antioxidant response element (Nrf2/ARE) luciferase reporter construct (HEK293; Signosis, Inc., Santa Clara, CA, USA). In these cells, redox-dependent stabilization of Nrf2 results in its translocation to the nucleus where it binds to the antioxidant response element (ARE) in the promoter located upstream of the firefly luciferase coding region. Thus, stabilization and translocation of Nrf2 to the nucleus leads to its binding and activation of the ARE. Activation of ARE results in luciferase expression, which is determined by measuring luminescence.

The HEK 293 Nrf2/ARE cells were grown to confluency and incubated with either $1 \mathrm{mg} / \mathrm{mL}$ ALB, $2 \mathrm{mM}$ MDA and $1 \mathrm{mM}$ AA, or $1 \mathrm{mg} / \mathrm{mL}$ ALB, $2 \mathrm{mM}$ MDA and $1 \mathrm{mM}$ MAA in the presence or absence of $1 \mathrm{mg} / \mathrm{mL}$ pharmaceutical DOX or $1 \mathrm{mg} / \mathrm{mL}$ ASC-free-DOX for $24 \mathrm{~h}$. After incubation, the growth media was removed and the cells were lysed using a passive lysis buffer as recommended by the manufacturer (Promega, Madison, WI, USA). The luciferase substrate (Signosis) was added to the lysates and luminescence was measured using a Turner Biosystems (Sunnyvale, CA, USA) LS-5B luminometer.

\subsection{Statistical Analysis}

Data are expressed as the mean \pm the standard error of the mean (SEM). Statistical analysis was performed using GraphPad Prism 7.04 (GraphPad Software Inc., La Jolla, CA, USA). Significance was determined by one-way ANOVA with Tukey's post-hoc test where appropriate. Differences were considered significant at $p \leq 0.05$.

\section{Clinical Perspectives}

Oxidative stress and chronic inflammation are associated with each other in many different diseases. Previous observations have shown that DOX has some benefits in the treatment of chronic inflammatory diseases. Therefore, we tested the hypothesis that DOX acts as an antioxidant and directly scavenges ROS to inhibit the production of MAA-adducts.

We demonstrate that DOX is able to directly scavenge superoxide, but not hydrogen peroxide, and inhibits the formation of MAA-adducts, which are known products of oxidative stress.

Reduction of oxidative stress by DOX may reduce inflammation, thereby providing benefit in the treatment of chronic inflammatory diseases. Our findings indicate that the non-antibiotic clinical efficacy of DOX observed in the treatment of these chronic inflammatory diseases may be explained, at least in part, by its direct and specific antioxidant properties.

Author Contributions: D.L.C., M.J.D., G.M.T., T.R.M., J.R.O., L.W.K., M.C.Z., and D.R.A. were involved in the planning and design of the studies; D.L.C., M.J.D., C.S., A.C., C.D.H., S.L.S., and J.T. performed the studies; D.L.C., M.J.D., G.M.T., T.R.M., J.R.O., L.W.K., M.C.Z, and D.R.A. prepared and reviewed the manuscript.

Funding: This work was supported by the University of Nebraska Department of Internal Medicine and the Division of Cardiology. EPR Spectroscopy data were collected in the University of Nebraska's EPR Spectroscopy 
Core, which is supported, in part, by a grant from the National Institute of General Medical Sciences of the National Institutes of Health (P30GM103335) awarded to the University of Nebraska's Redox Biology Center.

Conflicts of Interest: The authors declare no financial or scientific conflict of interests.

$\begin{array}{ll}\text { Abbreviations } \\ \text { AA } & \text { acetaldehyde } \\ \text { ALB } & \text { human serum albumin } \\ \text { ARE } & \text { antioxidant response element } \\ \text { ASC } & \text { ascorbic acid } \\ \text { CAT } & \text { catalase } \\ \text { CM } \bullet & \text { stable nitroxide radical } \\ \text { CMH } & \text { 1-hydroxy-3-methoxycarbonyl-2,2,5,5-tetramethylpyrrolidine } \\ \text { DETC } & \text { diethyldithiocarbamate } \\ \text { DTPA } & \text { diethylenetriaminepentaacetic acid } \\ \text { DOX } & \text { doxycycline } \\ \text { EPR } & \text { electron paramagnetic resonance } \\ \mathrm{H}_{2} \mathrm{O}_{2} & \text { hydrogen peroxide } \\ \mathrm{HX} & \text { hypoxanthine } \\ \text { ROS } & \text { reactive oxygen species } \\ \text { MDA } & \text { malondialdehyde } \\ \text { MAA } & \text { malondialdehyde-acetaldehyde } \\ \text { MTX } & \text { methotrexate } \\ \text { Nrf2 } & \text { nuclear factor (erythroid derived 2)-like 2 } \\ \mathrm{O}_{2} \bullet- & \text { superoxide } \\ \text { SOD } & \text { superoxide dismutase } \\ \text { XO } & \text { xanthine oxidase }\end{array}$

\section{References}

1. Griffin, M.O.; Fricovsky, E.; Ceballos, G.; Villarreal, F. Tetracyclines: A pleitropic family of compounds with promising therapeutic properties. Review of the literature. Am. J. Physiol. Cell Physiol. 2010, 299, C539-C548. [CrossRef] [PubMed]

2. Metz, L.M.; Li, D.K.B.; Traboulsee, A.L.; Duquette, P.; Eliasziw, M.; Cerchiaro, G.; Greenfield, J.; Riddehough, A.; Yeung, M.; Kremenchutzky, M.; et al. Trial of Minocycline in a Clinically Isolated Syndrome of Multiple Sclerosis. N. Engl. J. Med. 2017, 376, 2122-2133. [CrossRef]

3. O'Dell, J.R.; Elliott, J.R.; Mallek, J.A.; Mikuls, T.R.; Weaver, C.A.; Glickstein, S.; Blakely, K.M.; Hausch, R.; Leff, R.D. Treatment of early seropositive rheumatoid arthritis: Doxycycline plus methotrexate versus methotrexate alone. Arthritis Rheum. 2006, 54, 621-627. [CrossRef] [PubMed]

4. Stechmiller, J.; Cowan, L.; Schultz, G. The role of doxycycline as a matrix metalloproteinase inhibitor for the treatment of chronic wounds. Biol. Res. Nurs. 2010, 11, 336-344. [CrossRef] [PubMed]

5. Thompson, R.W.; Baxter, B.T. MMP inhibition in abdominal aortic aneurysms. Rationale for a prospective randomized clinical trial. Ann. N. Y. Acad. Sci. 1999, 878, 159-178. [CrossRef] [PubMed]

6. Baxter, B.T.; Pearce, W.H.; Waltke, E.A.; Littooy, F.N.; Hallett, J.W.; Kent, K.C., Jr.; Upchurch, G.R., Jr.; Chaikof, E.L.; Mills, J.L.; Fleckten, B.; et al. Prolonged administration of doxycycline in patients with small asymptomatic abdominal aortic aneurysms: Report of a prospective (Phase II) multicenter study. J. Vasc. Surg. 2002, 36, 1-12. [CrossRef] [PubMed]

7. Liu, J.; Xiong, W.; Baca-Regen, L.; Nagase, H.; Baxter, B.T. Mechanism of inhibition of matrix metalloproteinase-2 expression by doxycycline in human aortic smooth muscle cells. J. Vasc. Surg. 2003, 38, 1376-1383. [CrossRef]

8. Ravandi, A.; Boekholdt, S.M.; Mallat, Z.; Talmud, P.J.; Kastelein, J.J.; Wareham, N.J.; Miller, E.R.; Benessiano, J.; Tedgui, A.; Witztum, J.L.; et al. Relationship of IgG and IgM autoantibodies and immune complexes to oxidized LDL with markers of oxidation and inflammation and cardiovascular events: Results from the EPIC-Norfolk Study. J. Lipid Res. 2011, 52, 1829-1836. [CrossRef] 
9. Tsimikas, S.; Brilakis, E.S.; Lennon, R.J.; Miller, E.R.; Witztum, J.L.; McConnell, J.P.; Kornman, K.S.; Berger, P.B. Relationship of IgG and IgM autoantibodies to oxidized low density lipoprotein with coronary artery disease and cardiovascular events. J. Lipid Res. 2007, 48, 425-433. [CrossRef]

10. Kikugawa, K.; Ido, Y. Studies on peroxidized lipids. V. Formation and characterization of 1,4-dihydropyridine-3,5-dicarbaldehydes as model of fluorescent components in lipofuscin. Lipids 1984, 19, 600-608. [CrossRef]

11. Tuma, D.J.; Newman, M.R.; Donohue, T.M.; Sorrell, M.F., Jr. Covalent binding of acetaldehyde to proteins: Participation of lysine residues. Alcohol. Clin. Exp. Res. 1987, 11, 579-584. [CrossRef]

12. Binder, C.J.; Papac-Milicevic, N.; Witztum, J.L. Innate sensing of oxidation-specific epitopes in health and disease. Nat. Rev. Immunol. 2016, 16, 485-497. [CrossRef] [PubMed]

13. Busch, C.J.; Binder, C.J. Malondialdehyde epitopes as mediators of sterile inflammation. Biochim. Biophys. Acta 2017, 1862, 398-406. [CrossRef] [PubMed]

14. Tuma, D.J.; Thiele, G.M.; Xu, D.; Klassen, L.W.; Sorrell, M.F. Acetaldehyde and malondialdehyde react together to generate distinct protein adducts in the liver during long-term ethanol administration. Hepatology 1996, 23, 872-880. [CrossRef] [PubMed]

15. Anderson, D.R.; Duryee, M.J.; Shurmur, S.W.; Um, J.Y.; Bussey, W.D.; Hunter, C.D.; et al. Unique antibody responses to malondialdehyde-acetaldehyde (MAA)-protein adducts predict coronary artery disease. PLoS ONE 2014, 9, e107440. [CrossRef] [PubMed]

16. Duryee, M.J.; Klassen, L.W.; Schaffert, C.S.; Tuma, D.J.; Hunter, C.D.; Garvin, R.P.; Anderson, D.R.; Thiele, G.M. Malondialdehyde-acetaldehyde adduct is the dominant epitope after MDA modification of proteins in atherosclerosis. Free Radical Biol. Med. 2010, 49, 1480-1486. [CrossRef]

17. Willis, M.S.; Thiele, G.M.; Tuma, D.J.; Klassen, L.W. T cell proliferative responses to malondialdehyde-acetaldehyde haptenated protein are scavenger receptor mediated. Int. Immunopharmacol. 2003, 3, 1381-1399. [CrossRef]

18. Emeto, T.I.; Moxon, J.V.; Au, M.; Golledge, J. Oxidative stress and abdominal aortic aneurysm: Potential treatment targets. Clin. Sci. 2016, 130, 301-315. [CrossRef]

19. Rosenbaugh, E.G.; Roat, J.W.; Gao, L.; Yang, R.F.; Manickam, D.S.; Yin, J.X.; Schultz, H.D.; Bronich, T.K.; Batrakova, E.V.; Kabanov, A.V.; et al. The attenuation of central angiotensin II-dependent pressor response and intra-neuronal signaling by intracarotid injection of nanoformulated copper/zinc superoxide dismutase. Biomaterials 2010, 31, 5218-5226. [CrossRef]

20. Zimmerman, M.C.; Clemens, D.L.; Duryee, M.J.; Sarmiento, C.; Chiou, A.; Hunter, C.D.; Tian, J.; Klassen, L.W.; O’Dell, J.R.; Thiele, G.M.; et al. Direct antioxidant properties of methotrexate: Inhibition of malondialdehyde-acetaldehyde-protein adduct formation and superoxide scavenging. Redox Biol. 2017, 13, 588-593. [CrossRef]

21. Antoniak, D.T.; Duryee, M.J.; Mikuls, T.R.; Thiele, G.M.; Anderson, D.R. Aldehyde-modified proteins as mediators of early inflammation in atherosclerotic disease. Free Radical Biol. Med. 2015, 89, 409-418. [CrossRef] [PubMed]

22. Dikalov, S.I.; Dikalova, A.E.; Bikineyeva, A.T.; Schmidt, H.H.; Harrison, D.G.; Griendling, K.K. Distinct roles of Nox1 and Nox4 in basal and angiotensin II-stimulated superoxide and hydrogen peroxide production. Free Radical Biol. Med. 2008, 45, 1340-1351. [CrossRef]

23. Monacelli, F.; Acquarone, E.; Giannotti, C.; Borghi, R.; Nencioni, A.; Vitamin, C. Aging and Alzheimer's Disease. Nutrients 2017, 9.

24. Kunsch, C.; Medford, R.M. Oxidative stress as a regulator of gene expression in the vasculature. Circ. Res. 1999, 85, 753-766. [CrossRef] [PubMed]

25. Spychalowicz, A.; Wilk, G.; Sliwa, T.; Ludew, D.; Guzik, T.J. Novel therapeutic approaches in limiting oxidative stress and inflammation. Curr. Pharm. Biotechnol. 2012, 13, 2456-2466. [CrossRef] [PubMed]

26. Busch, C.J.; Hendrikx, T.; Weismann, D.; Jackel, S.; Walenbergh, S.M.; Rendeiro, A.F.; Weißer, J.; Puhm, F.; Hladik, A.; Göderle, L.; et al. Malondialdehyde epitopes are sterile mediators of hepatic inflammation in hypercholesterolemic mice. Hepatology 2017, 65, 1181-1195. [CrossRef]

27. Halliwell, B.; Gutteridge, J.M. Oxygen toxicity, oxygen radicals, transition metals and disease. Biochem. J. 1984, 219, 1-14. [CrossRef] 
28. Freeman, T.L.; Haver, A.; Duryee, M.J.; Tuma, D.J.; Klassen, L.W.; Hamel, F.G.; White, R.L.; Rennard, S.I.; Thiele, G.M. Aldehydes in cigarette smoke react with the lipid peroxidation product malonaldehyde to form fluorescent protein adducts on lysines. Chem. Res. Toxicol. 2005, 18, 817-824. [CrossRef]

29. Hill, G.E.; Miller, J.A.; Baxter, B.T.; Klassen, L.W.; Duryee, M.J.; Tuma, D.J.; Thiele, G.M. Association of malondialdehyde-acetaldehyde (MAA) adducted proteins with atherosclerotic-induced vascular inflammatory injury. Atherosclerosis 1998, 141, 107-116. [CrossRef]

30. McCaskill, M.L.; Kharbanda, K.K.; Tuma, D.J.; Reynolds, J.D.; DeVasure, J.M.; Sisson, J.H.; Wyatt, T.A. Hybrid malondialdehyde and acetaldehyde protein adducts form in the lungs of mice exposed to alcohol and cigarette smoke. Alcohol. Clin. Exp. Res. 2011, 35, 1106-1113. [CrossRef]

31. Rolla, R.; Vay, D.; Mottaran, E.; Parodi, M.; Traverso, N.; Arico, S.; Sartori, M.; Bellomo, G.; Klassen, L.W.; Thiele, G.M.; et al. Detection of circulating antibodies against malondialdehyde-acetaldehyde adducts in patients with alcohol-induced liver disease. Hepatology 2000, 31, 878-884. [CrossRef] [PubMed]

32. Thiele, G.M.; Duryee, M.J.; Anderson, D.R.; Klassen, L.W.; Mohring, S.M.; Young, K.A.; Benissan-Messan, D.; Sayles, H.; Dusad, A.; Hunter, C.D.; et al. Malondialdehyde-acetaldehyde adducts and anti-malondialdehyde-acetaldehyde antibodies in rheumatoid arthritis. Arthritis Rheumatol. 2015, 67, 645-655. [CrossRef] [PubMed]

33. Carson, J.S.; Xiong, W.; Dale, M.; Yu, F.; Duryee, M.J.; Anderson, D.R.; Thiele, G.M.; Baxter, B.T. Antibodies against malondialdehyde-acetaldehyde adducts can help identify patients with abdominal aortic aneurysm. J. Vasc. Surg. 2016, 63, 477-484. [CrossRef] [PubMed]

34. Xu, D.; Thiele, G.M.; Beckenhauer, J.L.; Klassen, L.W.; Sorrell, M.F.; Tuma, D.J. Detection of circulating antibodies to malondialdehyde-acetaldehyde adducts in ethanol-feed rats. Gastroenterology 1998, 115, 686-692. [CrossRef]

35. Willis, M.S.; Klassen, L.W.; Tuma, D.J.; Sorrell, M.F.; Thiele, G.M. Adduction of soluble proteins with malondialdehyde-acetaldehyde (MAA) induces antibody production and enhances T.-cell proliferation. Alcohol. Clin. Exp. Res. 2002, 26, 94-106. [CrossRef] [PubMed]

36. Kraus, R.L.; Pasieczny, R.; Lariosa-Willingham, K.; Turner, M.S.; Jiang, A.; Trauger, J.W. Antioxidant properties of minocycline: Neuroprotection in an oxidative stress assay and direct radical-scavenging activity. J. Neurochem. 2005, 94, 819-827. [CrossRef]

37. Budni, J.; Garcez, M.L.; de Medeiros, J.; Cassaro, E.; Bellettini-Santos, T.; Mina, F.; Quevedo, J. The Anti-Inflammatory Role of Minocycline in Alzheimer's Disease. Curr. Alzheimer Res. 2016, 13, 1319-1329. [CrossRef]

38. Soory, M. A role for non-antimicrobial actions of tetracyclines in combating oxidative stress in periodontal and metabolic diseases: A literature review. Open Dent. J. 2008, 2, 5-12. [CrossRef]

39. Yagan, A.; Kesim, S.; Liman, N. Effect of low-dose doxycycline on serum oxidative status, gingival antioxidant levels, and alveolar bone loss in experimental periodontitis in rats. J. Periodontol. 2014, 85, 478-489. [CrossRef]

40. Ozcinar, E.; Okatan, E.N.; Tuncay, E.; Eryilmaz, S.; Turan, B. Improvement of functional recovery of donor heart following cold static storage with doxycycline cardioplegia. Cardiovasc Toxicol. 2014, 14, 64-73. [CrossRef]

41. Antonio, R.C.; Ceron, C.S.; Rizzi, E.; Coelho, E.B.; Tanus-Santos, J.E.; Gerlach, R.F. Antioxidant effect of doxycycline decreases MMP activity and blood pressure in SHR. Mol. Cell. Biochem. 2014, 386, 99-105. [CrossRef] [PubMed]

42. Mittal, M.; Siddiqui, M.R.; Tran, K.; Reddy, S.P.; Malik, A.B. Reactive oxygen species in inflammation and tissue injury. Antioxid Redox Signal. 2014, 20, 1126-1167. [CrossRef] [PubMed]

43. Siti, H.N.; Kamisah, Y.; Kamsiah, J. The role of oxidative stress, antioxidants and vascular inflammation in cardiovascular disease (a review). Vascul. Pharmacol. 2015, 71, 40-56. [CrossRef] [PubMed]

44. Dikalov, S.; Griendling, K.K.; Harrison, D.G. Measurement of reactive oxygen species in cardiovascular studies. Hypertension 2007, 49, 717-727. [CrossRef] [PubMed]

(C) 2018 by the authors. Licensee MDPI, Basel, Switzerland. This article is an open access article distributed under the terms and conditions of the Creative Commons Attribution (CC BY) license (http:/ / creativecommons.org/licenses/by/4.0/). 